\title{
Investigations of a Type 316L Steam Dryer Plate Material Suffering from IGSCC After a Few Years in BWR Conditions.
}

\author{
Juha-Matti Autio ${ }^{1}$, Ulla Ehrnstén ${ }^{1}$, Roman Mouginot $^{2}$, Janne Pakarinen $^{3}$, Massimo Cocco ${ }^{4}$ \\ 1. VTT Technical Research Centre of Finland, Espoo, Finland \\ 2. Aalto University School of Engineering, Espoo, Finland \\ ${ }^{3 .}$ University of Wisconsin-Madison, Madison, USA \\ 4. Forsmark Kraftgrupp, Östhammar, Sweden
}

Detailed microstructural characterization has been performed on a sample made of Type 316L stainless steel, removed from a boiling water reactor (BWR) steam dryer inner roof plate, which had suffered from intergranular stress corrosion cracking (IGSCC) after only a few years of operation. The aim of the characterisation was to increase the understanding of possible material related characteristics that could have affected the observed cracking.

A failure analysis conducted by the plant concluded that the failure mechanism was IGSCC, although a note was made that it is not typical in such a short period of time, especially in a low carbon material. The failure analysis included SEM, EDS, oxalic acid etching and EBSD to verify IGSCC as the most probable failure mechanism.

In the additional investigations focussing on detailed investigation of the material characteristics, a nonhomogeneous microstructure shown in Figure 1 was confirmed by EBSD and presence of alphamartensite in the mid-thickness of the plate, as a consequence of deformation, was observed, Figure 2. Macro-segregation bands were observed with consequent fluctuations in the composition of especially $\mathrm{Ni}$ and $\mathrm{Cr}$, Figure 3. Corresponding hardness difference over the bands was measured with a nanohardness tester, Figure 3. Also very high surface hardness, obviously from surface grinding during manufacturing, was measured on both sides of the $6 \mathrm{~mm}$ thick plate. The macro-segregation is a result from continuous casting, which does not include upset forging as a manufacturing step. The reasons for the non-homogeneous microstructure through the plate thickness shown in Figure 1 maybe caused by the aforementioned factors as well as the final rolling passes.

The non-homogeneous material and the high surface hardness are both material characteristics which have increased this material's susceptibility to IGSCC. High residual stresses from welding, which were also very likely in this case (based on received information), have increased the IGSCC susceptibility of the plate. The thickness of the deformed layer with high hardness was so thin, that it would not be detected using conventional techniques, e.g. Rockwell $\mathrm{C}$ hardness, used for quality assurance during manufacturing. To mitigate the risk for IGSCC due diligence must be taken at all steps of manufacturing and assembly. Ensuring safe and economic nuclear power plant operation for 60 years and above, it is of utmost importance that nuclear materials fulfil stringent requirements.

\section{References:}

[1] J-M Autio, U Ehrnstén, Microstructural chracterisation of a Type 316L material removed from a BWR steam dryer, VTT Research report VTT-R-00500-14, (2014)

[2] U Ehrnstén, in "Comprehensive nuclear materials", Vol. 5 (2012), p. 93 
[3] M Morra, Process Parameters Affecting inhomogeneity of Material Microstructure, SSM research 2012:70, (2012)

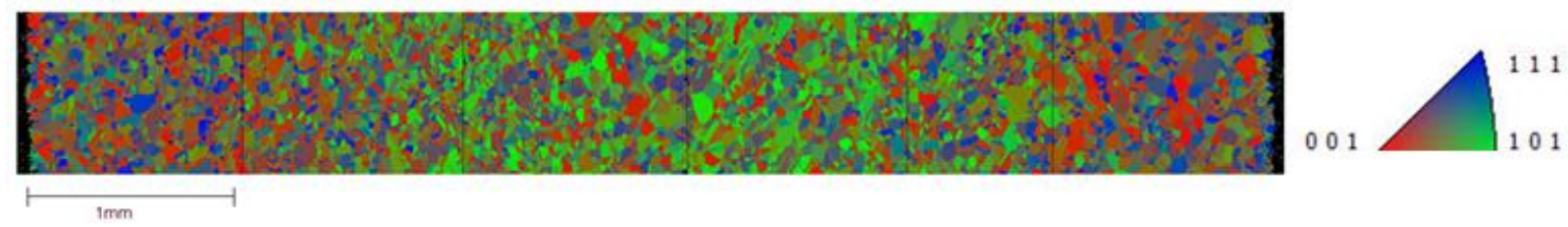

Figure 1 An EBSD map from the cross-section of the sample, showing an inhomogeneous grain orientation through the thickness of the plate. This is most likely caused by manufacturing parameters, e.g. deformation and temperatures in a non-homogenous material during rolling.
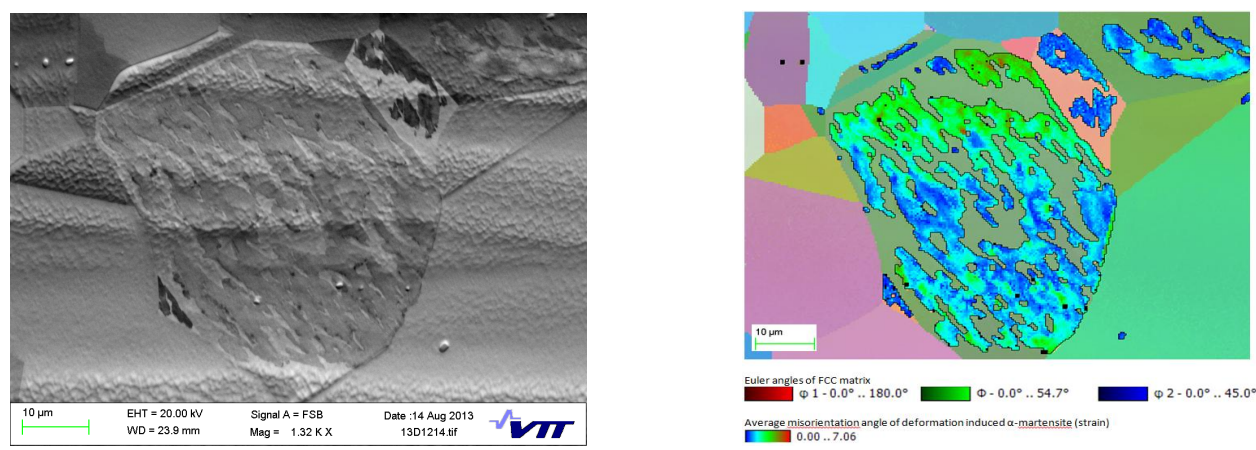

Figure 2. An FSB image of a partially deformed austenite grain is shown on the left side and an EBSD analysis on the right side. The images show a grain which has been partially transformed to alphamartensite (BCC) in an austenite (FCC) matrix. The sub-grain structure of the partially deformed grain is identified as alpha-martensite and the average misorientation angle of the BCC structure is shown as a thermal map in the EBSD analysis.
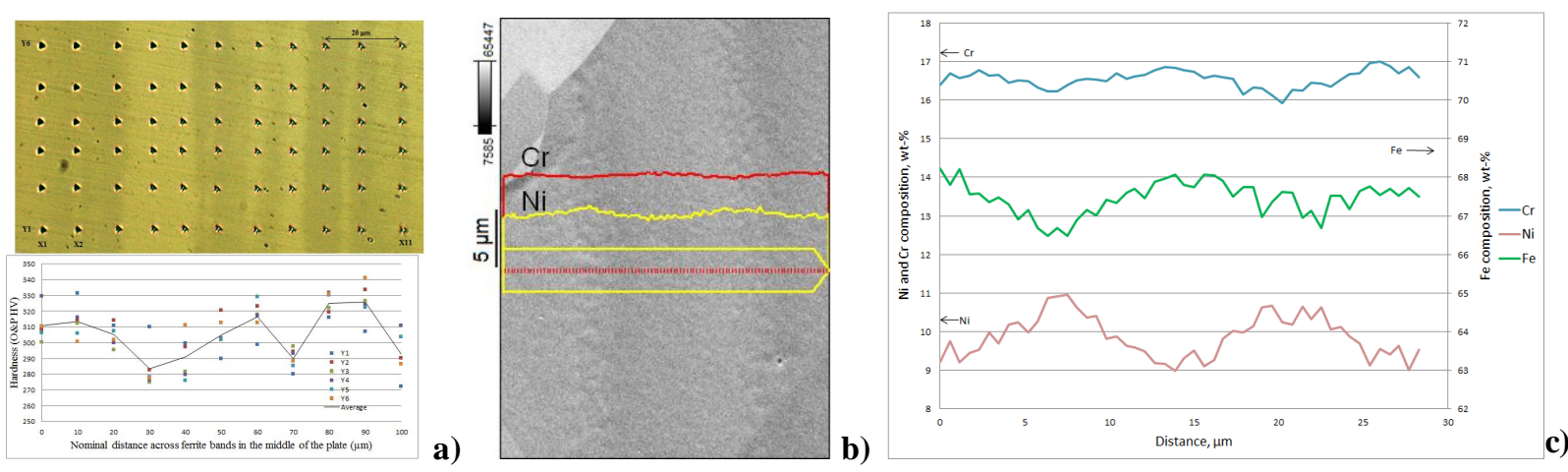

Figure 3. Image a) shows nano-hardness measurements over macrosegregation bands and their average values below in a graph, showing a fluctuation in the hardness values. Similar fluctuation was also measured in the composition over the macrosegreation bands, which is shown in images b), where $\mathrm{Ni}$ is marked as a yellow line and $\mathrm{Cr}$ as a red line, and in image c), where the compositions are shown in a graph. 